\title{
Hypersexual behavior in a large online sample: Individual characteristics and signs of coercive sexual behavior
}

\author{
JANNIS ENGEL*, ANDREA KESSLER, MARIA VEIT, CHRISTOPHER SINKE, IVO HEITLAND, \\ JONAS KNEER, UWE HARTMANN and TILLMANN H. C. KRUGER
}

\author{
Department of Psychiatry, Social Psychiatry and Psychotherapy, Division of Clinical Psychology and Sexual Medicine, \\ Hannover Medical School, Hannover, Germany
}

(Received: October 30, 2018; revised manuscript received: March 5, 2019; accepted: March 15, 2019)

\begin{abstract}
Background and aims: Despite the high prevalence of perceived problems relating to symptoms of hypersexual disorder (HD), important aspects remain underinvestigated. This study examines symptoms of depression, symptoms of problematic cybersex, and coercive sexual behavior in a large online sample from a German-speaking population. Methods: In an online survey, $N=1,194$ ( $n=564$ women) participated in this study and completed measures including self-report questionnaires to assess depressive symptoms (PHQ-9), HD (HBI-19), symptoms of problematic cybersex (s-IATsex), as well as questions characterizing participants sexually, including fantasies and actual sexual coercive behaviors. Results: Men reported increased levels of HD symptom severity, pornography consumption, masturbation, and partnered sexual activity. Moreover, $59 \%$ of men and $18 \%$ of women reported fantasies of sexual coercion, whereas $21 \%$ of men and $4 \%$ of women reported acts of sexual coercion. Moderated regression analyses showed that symptoms of depression as well as sexual coercive fantasies and behaviors were associated with levels of HD symptom severity. Problematic cybersex, total sexual outlet (TSO), pornography consumption, and number of sexual partners were also associated with HD symptom severity. Interaction effects indicated that, in women, the connection of TSO as well as pornography was more strongly associated with levels of HD symptom severity than in men. Conclusions: This survey indicated that levels of HD symptom severity are often associated with severe intraand interpersonal difficulties. Furthermore, the amount of sexual activity seems to be more strongly connected to levels of HD symptom severity in women than in men.
\end{abstract}

Keywords: hypersexuality, compulsive sexual behavior disorder, sexual coercion, depressive symptoms, problematic cybersex

\section{BACKGROUND}

Kafka (2010) proposed the atheoretical term "hypersexual disorder" (HD) as a category to be included in the fifth edition of Diagnostic and Statistical Manual of Mental Disorders (DSM-5; American Psychiatric Association [APA], 2013). Furthermore, hypersexual behavior has been proposed for inclusion as compulsive sexual behavior disorder in ICD-11 (Grant et al., 2014). The suggested category is characterized by a recurrent pattern of failure to control intense, repetitive sexual impulses, or urges resulting in repetitive sexual behavior that causes clinically significant distress or impairments in important areas of functioning, for example, repeated relationship disruption (Kraus et al., 2018). Moreover, the diagnosis includes the continuation of repetitive sexual behavior despite adverse consequences or deriving little or no satisfaction from it. The exclusion in the diagnosis is psychological distress related to moral judgments or disapproval about sexual impulses, urges, or behavior (Kraus et al., 2018). In principal, the proposed criteria of HD (Kafka, 2010) are similar to the proposed criteria of compulsive sexual behavior. However, the proposed criteria of HD did not explicitly exclude the diagnosis due to distress related to moral judgments about sexual activities. Moreover, they did not include the continuation of sexual behavior despite deriving little or no satisfaction from it as a criterion. This study investigates possible characteristics of hypersexual behavior, such as symptoms of depression, symptoms of problematic cybersex, and coercive sexual behavior. To examine these characteristics, an online survey was conducted in a large German-speaking population, including both women and men.

Most data on the prevalence of hypersexual behavior are restricted to men, while findings on women and non-heterosexual men remain sparse (for a review, see Montgomery-Graham, 2017). It appears that hypersexual behavior is more common in men than in women (Skegg, Nada-Raja, Dickson, \& Paul, 2010; Walton, Cantor,

* Corresponding author: Jannis Engel; Department of Psychiatry, Social Psychiatry and Psychotherapy, Hannover Medical School, Carl-Neuberg-Str. 1, 30625 Hannover, Germany; Phone: +49 511 532 2631; Fax: +49 511 8407; E-mail: engel.jannis@mh-hannover.de

This is an open-access article distributed under the terms of the Creative Commons Attribution-NonCommercial 4.0 International License, which permits unrestricted use, distribution, and reproduction in any medium for non-commercial purposes, provided the original author and source are credited, a link to the CC License is provided, and changes - if any - are indicated. 
Bhullar, \& Lykins, 2017). Recent data shown by representative surveys of women $(n=1,174)$ and men $(n=1,151)$ found that $7 \%$ of women and $10.3 \%$ of men in the United States showed clinically relevant levels of distress and/or impairment due to difficulties in controlling sexual urges, feelings, and behaviors (Dickenson, Gleason, Coleman, \& Miner, 2018).

Cybersex is an umbrella term for various online sexual activities, for example, online pornography consumption (Wéry \& Billieux, 2017). The "triple-A engine" explains the rise in cybersex - consisting of "Access-AffordabilityAnonymity," which are all features of the Internet that have become more pronounced over time (Cooper, 1998). In fact, representative surveys indicate that a majority of men $(64 \%-70 \%)$ and a quarter to a third of women $(23 \%-33 \%)$ have watched pornography in the past year (Grubbs, Kraus, \& Perry, 2018; Rissel et al., 2016). Pornography consumption varies with gender and age, with men consuming more than women (Janghorbani \& Lam, 2003; Træen, Nilsen, \& Stigum, 2006).

Hypersexual behavior and symptoms of affective disorders are often connected. One previous study (Weiss, 2004) estimated the prevalence of depression in a sample of male sex addicts $(N=220)$ to be $28 \%$, compared to an estimated high of $12 \%$ in the general male population. Combined, the results suggest a high range of $28 \%-69 \%$ for comorbid depressive disorders in hypersexual behavior (Kafka \& Hennen, 2002; Raymond, Coleman, \& Miner, 2003; Weiss, 2004).

Hypersexual behavior is often acted out through excessive pornography consumption in combination with masturbation, and may function as a dysfunctional coping strategy, for example, to avoid negative affect or tension (Reid, Carpenter, Spackman, \& Willes, 2008). To date, there seems to be no clear connection between hypersexual behavior and sexual coercion. However, it was hypothesized that increasing consumption of pornography comes with a significant association between supportive offensive sexual attitudes and actual offensive sexual acts, especially when consuming sexually violent pornography (Hald, Malamuth, \& Yuen, 2010). Online, but particularly in real-life contacts, sexual coercion remains a major concern in our societies: $9.4 \%$ of women in the United States have been raped in an intimate relationship, whereas $16.9 \%$ of women and $8.0 \%$ of men have experienced sexual coercion other than rape (Black et al., 2011).

\section{Aims}

This study examined intra- and interpersonal difficulties associated with levels of HD symptom severity in women and men in large German-speaking population. Investigated intrapersonal difficulties included symptoms of depression; investigated interpersonal difficulties were fantasies of sexual coercion and acts of sexual coercion. Based on previous studies (Kafka \& Hennen, 2002; Raymond et al., 2003; Weiss, 2004) that showed high comorbid rates of depression in hypersexual behavior, it was hypothesized that levels of HD symptom severity are associated with higher levels of depressive symptoms. Based on preliminary findings that hypersexual behavior and sexual coercive attitudes may be interlinked (Hald et al., 2010), we would like to explore if fantasies and actual acts of sexual coercion are associated with hypersexual behavior. Moreover, increased sexual behavior was assumed to predict levels of HD symptom severity. Due to the emerging possibilities of the Internet (Cooper, 1998), we also assumed that levels of HD symptom severity were connected to symptoms of problematic cybersex and pornography consumption.

\section{METHODS}

\section{Subjects}

The initial sample consisted of $N=2,069$ individuals ( $n=896$ women, $n=28$ no information; see Figure 1 ).

The final sample consisted of $N=1,194$ individuals [ $n=564$ women, age: $M=33.83$ years, standard deviation $(S D)=15.25 ; \quad n=630$ men, age: $M=50.52$ years, $S D=19.34]$ who completed the questionnaires. Data from a number of participants had to be excluded from the analyses: $n=687$ did not complete the questionnaire and $n=188$ were either younger than 18 years or did not mention their age. The average age of participants was $32.99(S D=10.78)$ years. Thirty-two percent reported having reached at least a university entrance level of education. The majority identified themselves as heterosexual $(83 \%)$, fewer reported having a bisexual orientation $(13 \%)$, and only $4 \%$ identified themselves as homosexual. The majority of participants was not married (75\%); however, around $70 \%$ were in a relationship. Finally, $60 \%$ of participants had no children (Table 1).

\section{Procedure}

We conducted an online study among a German-speaking population. Data were collected using SoSci-Survey, a freeaccess, online survey platform. A link to the site was posted on self-help platforms for hypersexual behavior and social media websites and sent to personal contacts and the mailing list of the University of Hildesheim, Germany. Moreover, online newspapers published articles about the study and included a link to it in their articles. Some of the websites that included the link explicitly stated that "sex addicts" were being sought. Participants gave their informed consent and could leave their contact information for further studies at the end.

\section{Measures}

Hypersexual Behavior Inventory-19 (HBI-19). In this study, the German version of the HBI-19 (Reid, Garos, Carpenter, \& Coleman, 2011) was used to assess levels of HD symptom severity. Its 19 items are based on the criteria that were proposed for the HD categorization in the DSM-5 (Kafka, 2010). Responses to the items are recorded on a 5-point Likert scale ranging from 1 (never) to 5 (very often). A preliminary cut-off point of $\geq 53$ was proposed on the basis of two clinical and two control samples (Reid et al., 2011), but later was rejected on the basis of a larger sample (Böthe, Bartók, et al., 2018). 


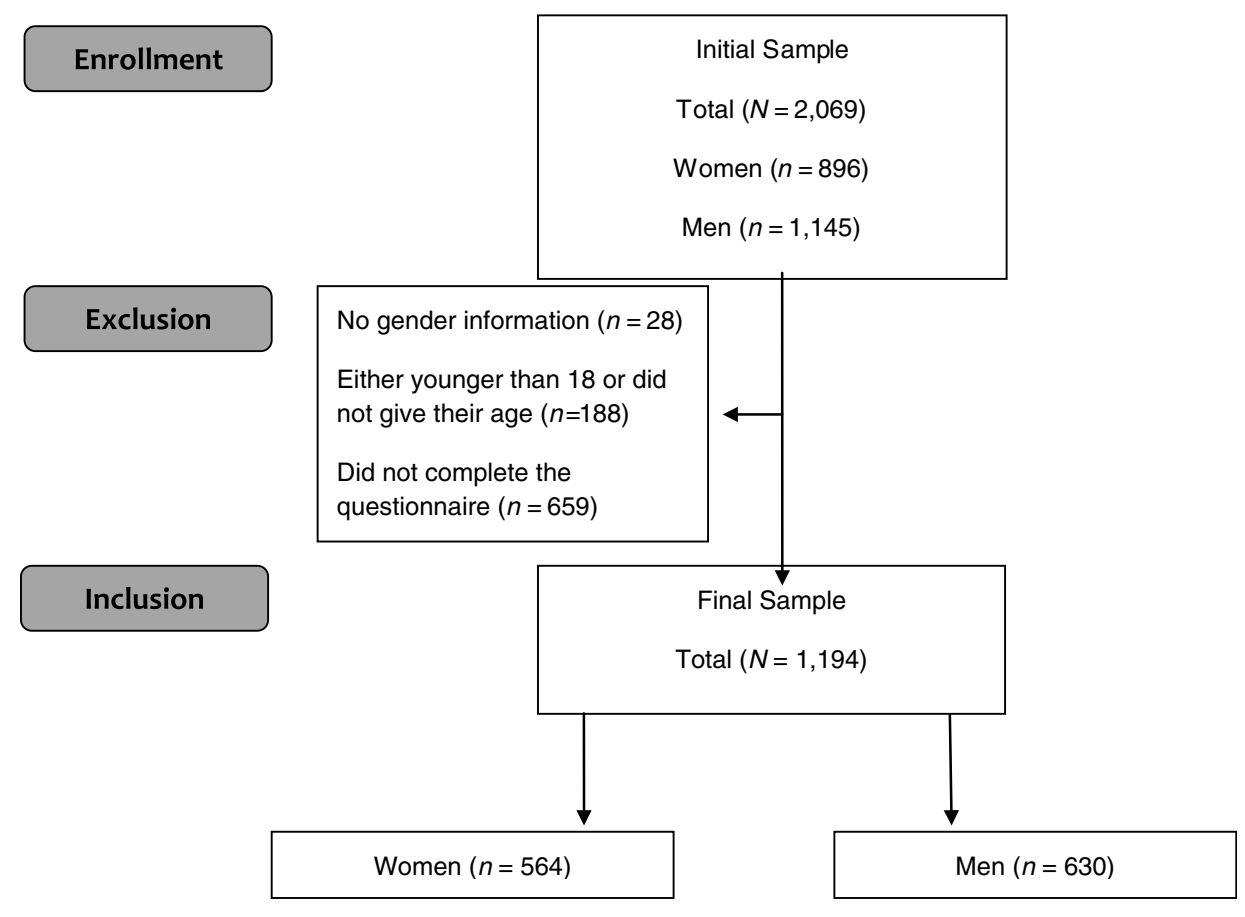

Figure 1. Recruitment of participants

Table 1. Descriptive statistics

\begin{tabular}{lll}
\hline Sociodemographic variables & \multicolumn{1}{c}{$N$} & $\%$ \\
\hline Education (no school graduation/secondary school/secondary modern school/ & $15 / 107 / 385 / 383 / 304$ & $1 / 9 / 32 / 32 / 26$ \\
university entrance qualification/studies) & & \\
Sexual orientation (heterosexual/bisexual/homosexual) & $987 / 162 / 45$ & $83 / 13 / 4$ \\
Family status (single/married/divorced or separated/widowed) & $756 / 300 / 128 / 10$ & $63 / 25 / 11 / 1$ \\
Partnership (no partner/with partner less than a year/with partner over a year) & $364 / 115 / 715$ & $30 / 10 / 60$ \\
Number of children $(0 / 1 / 2 / 3 / \geq 4)$ & $719 / 185 / 198 / 66 / 26$ & $60 / 15 / 17 / 6 / 2$ \\
\hline
\end{tabular}

Patient Health Questionnaire (PHQ-9). To assess depressive symptoms, we used the German version of the PHQ-9 (Kroenke \& Spitzer, 2002; Löwe, Kroenke, Herzog, \& Gräfe, 2004). Its nine items are based on the DSM-5 criteria (APA, 2013) for major depressive disorder. Patients are asked whether they have experienced the listed symptoms over the past 2 weeks. In this study, we analyzed the PHQ-9 dimensionally. Responses are captured on a 4-point Likert scale and range from 0 (not at all) to 3 (nearly every day), giving an item score range of $0-27$. The item score can be interpreted as a measure of severity (Kroenke \& Spitzer, 2002).

Short Internet Addiction Test (s-IATsex). Symptoms of problematic cybersex were assessed using a modified version of the s-IATsex (Brand et al., 2011). Responses are recorded on a 5-point Likert scale ranging from never to very often.

Sexual behavior. This self-designed questionnaire examined the sexual behavior of participants and included items about age, sexual orientation, total sexual outlet (TSO) differentiated by masturbation and experienced with a partner, consumption of pornography, relationship status, and number of sexual partners in the past year. Further questions asked whether participants "have ever fantasized about forcing someone to perform sexual acts?" or "have ever forced someone to perform sexual acts?"

\section{Statistical analyses}

All data analyses were performed on SPSS version 24 $\left(\right.$ IBM $^{\circledR}$ Corporation, Armonk, NY, USA) for Windows. Statistical analyses were carried out using independent $t$-tests or Fisher's exact tests for dichotomous variables and tables larger than $2 \times 2$.

Hierarchical multiple linear regression analyses were employed to test the association between symptoms of depression (as measured with PHQ-9) and hypersexuality (HBI-19) with gender as a moderator variable. The PHQ-9, as a metric variable, was mean-centered. An interaction term was created by multiplying the mean-centered variable of depressive symptoms and gender. Changes in the determination coefficient $\left(\Delta R^{2}\right)$ were used to assess the significance of the association between depression and hypersexuality. Interaction effects are shown with simple slopes. Low values for the variables are estimated for subjects with values $1 S D$ below the group's mean, high values are estimated for the subjects with values $1 S D$ above the group's mean. 


\section{Ethics}

The study procedures were carried out in accordance with the Declaration of Helsinki. The institutional review board of the Hannover Medical School approved the study. All participants were informed about the study and all provided signed informed consent.

\section{RESULTS}

\section{Comparisons between genders}

A comparison of HBI-19 scores between men $(M=50.52$, $S D=19.34)$ and women $(M=33.82, S D=15.25)$ revealed significantly higher scores in men, $t(1,174)=16.65$, $p<.001, d=0.95$. A cut-off score sum score of 53 has been proposed for HBI-19 (Reid et al., 2011) but ultimately been questioned (Bőthe, Kovács, et al., 2018). If the old cutoff score would have been applied, there would be a considerably large number of women and men that showed increased levels of HD symptom severity. A total of $N=360$ individuals $(n=74$ or $13.1 \%$ of women; $n=286$ or $45.4 \%$ of men) had an HBI-19 sum score of at least 53; the remaining $n=834$ individuals ( $n=490$ women; $n=344$ men) had an HBI-19 sum score $\Sigma<53$ (Table 2).

In this study, both groups showed elevated rates of depressive symptoms in men, the sum score of PHQ-9 (women, $M=15.41, S D=5.12$; men, $M=16.76, S D=$ $5.19)$ indicated that both genders showed moderate to severe symptoms of depression, $t(1,192)=-4.491, \quad p<.001$, $d=0.27$. Sixty-one percent of women and $49 \%$ of men reported at least moderate to severe symptoms of depression.

On average, men reported spending $6.64 \mathrm{hr}(S D=11.98)$ of pornography consumption in the past week compared to $1.05 \mathrm{hr}(S D=3.06)$ in women, $t(705)=11.194, p<.001$, $d=0.657$. Moreover, men reported to have a higher TSO experienced with a partner $(M=2.64, S D=5.51)$ compared to women $(M=1.55, S D=2.85), t(953)=4.322, p<.001$, $d=0.252$, as well as a higher TSO through masturbation in men $(M=7.87, S D=9.63)$ compared to women $(M=3.01$, $S D=5.69), t(1,033)=10.688, p<.001, d=0.623$. Furthermore, men reported more sexual partners in the past year $(M=2.77, S D=10.42)$, compared to women $(M=2.77$, $S D=10.42), \quad t(978)=3.683, p<.001, \quad d=0.208$. The same was found for the problematic cybersex, where men also reached significantly higher scores than women, $t(1,018)=20.9, p<.001, d=1.121$.

In both genders, there were a considerably large number of individuals who reported fantasies of sexual coercive behavior. About $30 \%$ of women $(n=119)$ and $60 \%$ of men reported that they have fantasized of forcing someone to perform sexual acts, $\chi^{2}(1)=178.374, p<.001$. Moreover, men had significantly more often engaged in sexual coercive behavior, $\chi^{2}(1)=58.563, p<.001$. Approximately, $20 \%$ of the men $(n=117)$ and $4 \%$ of women $(n=24)$ reported to have forced someone to perform sexual acts.

\section{Main analyses}

Correlations between variables are displayed in Table 3. A moderated regression analysis for symptoms of depression (PHQ-9 as predictor), gender (moderator), and levels of HD symptom severity (HBI-19) was calculated. In the first step, the PHQ-9 sum score explained $8.4 \%$ of the HBI-19 sum score variance, $F(1,1192)=110.2, p<.001$. In the second step, the gender led to a significant increase of variance explanation, $\Delta R^{2}=.222, \Delta F(1,1191)=381.52, p<.001$. The interaction of the PHQ-9 sum score and gender increased variance explanation, $\Delta R^{2}=.009, \Delta F(1,1190)=$ $15.11, p<.001$. Overall, the regression model was significant and explained $31.5 \%$ variance of the HBI-19 sum score, $R^{2}=.315, F(3,1190)=182.751, p<.001$.

A second moderated regression analysis for fantasies of sexual coercion (as predictor), gender (moderator), and levels of HD symptom severity (HBI-19) was calculated. In the first step, fantasies of sexual coercion explained $11.3 \%$ of the HBI-19 sum score variance, $F(1,1192)=$ $151.96, p<.001$. In the second step, the gender led to a

Table 2. Comparison between genders

\begin{tabular}{|c|c|c|c|c|c|c|c|}
\hline \multirow[b]{2}{*}{ Variable } & \multicolumn{2}{|r|}{ Women } & \multicolumn{2}{|r|}{ Men } & \multirow[b]{2}{*}{ Test statistic } & \multirow[b]{2}{*}{$p$ value } & \multirow[b]{2}{*}{ Effect size $(d)$} \\
\hline & $N$ & $M(S D)$ & $N$ & $M(S D)$ & & & \\
\hline HBI-19 & 564 & $33.82(15.25)$ & 630 & $50.52(19.34)$ & $t(1,174)=16.65$ & $<.001$ & 0.950 \\
\hline PHQ & 564 & $16.76(5.19)$ & 630 & $15.42(5.13)$ & $t(1,192)=-4.491$ & $<.001$ & 0.270 \\
\hline s-IATsex & 564 & $15.44(6.73)$ & 629 & $26.91(11.78)$ & $t(1,018)=20.9$ & $<.001$ & 1.121 \\
\hline Consumption pornography & 549 & $1.05(3.06)$ & 617 & $6.64(11.98)$ & $t(705)=11.194$ & $<.001$ & 0.657 \\
\hline TSO-experienced with a partner & 558 & $1.55(2.85)$ & 622 & $2.64(5.51)$ & $t(953)=4.322$ & $<.001$ & 0.252 \\
\hline TSO-masturbation & 555 & $3.01(5.69)$ & 626 & $7.87(9.63)$ & $t(1,034)=10.688$ & $<.001$ & 0.623 \\
\hline \multirow[t]{2}{*}{$\begin{array}{l}\text { Number of sexual partners in } \\
\text { the past year }\end{array}$} & 562 & $2.77(10.42)$ & 626 & $6.01(19.09)$ & $t(987)=3.683$ & $<.001$ & 0.208 \\
\hline & & Yes & & Yes & & & \\
\hline Sexual coercive behavior & 564 & 24 & 630 & 117 & $\chi^{2}(1)=58.563$ & $<.001$ & \\
\hline Sexual coercive fantasies & 564 & 119 & 630 & 373 & $\chi^{2}(1)=178.374$ & $<.001$ & \\
\hline
\end{tabular}

Note. SD: standard deviation; HBI-19: Hypersexual Behavior Inventory measuring hypersexual behavior; PHQ-9: score of Patient Health Questionnaire-9 measuring depressive symptoms; s-IATsex: score of short Internet Addiction Test Sex measuring problematic cybersex; TSO-coitus: number of total sexual outlets experienced with a partner; TSO-masturbation: number of total sexual outlets experienced through masturbation. 
Table 3. Correlations and Cramer's $V$

\begin{tabular}{|c|c|c|c|c|c|c|c|c|}
\hline & PHQ-9 & s-IATsex & $\begin{array}{c}\text { Fantasies of } \\
\text { sexual coercive } \\
\text { behavior }\end{array}$ & $\begin{array}{c}\text { Actual sexual } \\
\text { coercive } \\
\text { behavior }\end{array}$ & $\begin{array}{c}\text { TSO- } \\
\text { masturbation }\end{array}$ & $\begin{array}{l}\text { TSO- } \\
\text { with a } \\
\text { partner }\end{array}$ & $\begin{array}{l}\text { Pornography } \\
\text { consumption }\end{array}$ & $\begin{array}{l}\text { Number of } \\
\text { partners } \\
\text { (past year) }\end{array}$ \\
\hline PHQ-9 & - & & & & & & & \\
\hline s-IATsex & $.171^{* *}$ & - & & & & & & \\
\hline $\begin{array}{l}\text { Fantasies of sexual } \\
\text { coercive behavior }\end{array}$ & .123 & $.451 * *$ & - & & & & & \\
\hline $\begin{array}{l}\text { Actual sexual coercive } \\
\text { behavior }\end{array}$ & .116 & $.377 * *$ & $.326^{* *}$ & - & & & & \\
\hline TSO-masturbation & .064 & $.429 * *$ & $.368 * *$ & $.328 * *$ & - & & & \\
\hline TSO-with a partner & -.150 & $.180^{* *}$ & .183 & $.226^{*}$ & $.356^{* *}$ & - & & \\
\hline $\begin{array}{l}\text { Pornography } \\
\text { consumption }\end{array}$ & .030 & $.454 * *$ & $.452 * *$ & $.336^{* *}$ & $.330 * *$ & $.158^{* *}$ & - & \\
\hline $\begin{array}{l}\text { Number of partners } \\
\text { (past year) }\end{array}$ & .004 & $.174 * *$ & $.245^{*}$ & $.244 * *$ & $.208 * *$ & $.481^{* *}$ & $.254 * *$ & - \\
\hline
\end{tabular}

Note. Bivariate Pearson's correlation of metric variables. Cramer's $V$ was used if nominal variables were included. PHQ-9: score of Patient Health Questionnaire-9 measuring depressive symptoms; s-IATsex: score of short Internet Addiction Test Sex measuring problematic cybersex; TSO-masturbation: number of total sexual outlets experienced through masturbation.

${ }^{*} p<.05$ (asymptotic significances; two-tailed). ${ }^{* *} p<.01$ (asymptotic significances; two-tailed).

significant increase of variance explanation, $\Delta R^{2}=.111$, $\Delta F(1,1191)=161.1, p<.001$. The interaction of the PHQ-9 sum score and gender did not lead to a significant variance explanation, $\Delta R^{2}<.001, \Delta F(1,1190)=0.04$, $p=.834$. Overall, the regression model was significant and explained $21.9 \%$ variance of the HBI-19 sum score, $R^{2}=.219, F(3,1190)=111.09, p<.001$.

A third moderated regression analyses for acts of sexual coercion (as predictor), gender (moderator), and levels of HD symptom severity (HBI-19) were calculated. In the first step, acts of sexual coercion explained $6.8 \%$ of the HBI-19 sum score variance, $F(1,1192)=87.2, p<.001$. In the second step, the gender led to a significant increase of variance explanation, $\Delta R^{2}=.146, \Delta F(1,1191)=220.38$, $p<.001$. The interaction of the PHQ-9 sum score and gender did not lead to a significant variance explanation $\Delta R^{2}=.003, \Delta F(1,1190)=4.69, p=0.031$. Overall, the regression model was significant and explained $21.7 \%$ variance of the HBI-19 sum score $R^{2}=.217, F(3,1190)=$ $109.78, p<.001$.

Further moderated regression analyses using as predictors problematic cybersex, TSO experienced through masturbation or with a partner, time of consumed pornography, and number of sexual partners in the past year, gender (moderator), and levels of HD symptom severity (HBI-19) were calculated. The first step in all further models led to significance of the HBI-19 score variance. Furthermore, in the second step, the gender of the participant led to a significant increase of variance explanation in all models. Overall, the different regression models were all significant. In the third step, the interactions were significant in problematic cybersex, TSO experienced with a partner or masturbation, time of pornography consumption, but not in number of partners in the past year. Further values for all moderated regression analyses can be seen in Table 4. The interaction effects are illustrated with simple slopes analyses in Figure 2. Correlational analyses investigated differences between levels of HD symptom severity and sexual behavior, as separated by gender of participant. In women, significant correlations with levels of HD symptom severity could be seen with partnered sexual activity $(r=.267$, $p<.001)$, time of pornography consumption $(r=.429$, $p<.001)$, and TSO-masturbation $(r=.461, p<.001)$. In men, there was no significant correlation between levels of HD symptom severity and partnered sexual activity $(r=.075, p<.001)$, and significant but weaker correlations with pornography consumption $(r=.305, p<.001)$, and TSO-masturbation $(r=.239, p<.001)$. We calculated Fishers' $z$ to assess the significance of the difference between correlation coefficients. Comparisons between correlations of levels of HD symptom severity with partnered sexual activity $(z=-3.4, p<.001)$, pornography consumption $(z=-2.44, p=.007)$, and TSO-masturbation $(z=-3.1$, $p=.001)$ indicated significantly higher correlations in women compared to men.

Additional analyses were performed using the proposed preliminary cut-off sum score of 53 for which HBI-19 can be seen in Supplementary Material.

\section{DISCUSSION}

In this online study, a sample of 1,194 women and men completed questionnaires on levels of HD symptom severity, depression, and sexual coercion. Our aim was to investigate potential associations between depressive symptoms, sexual behavior, and fantasies about and actual behavior of forcing someone to perform sexual acts, moderated by gender. We were able to reach a large number of women and men to answer intimate questions about sexual fantasies and behavior. On average, levels of HD symptom severity were higher in men than in women. However, a considerable amount of women $(n=74)$ reported elevated levels of HD symptom severity. The main results of this study are that symptoms of depression, problematic cybersex, TSO experienced with a partner or through masturbation, number 
Table 4. Moderated regression analyses with the HBI-19 sum score as dependent variable

\begin{tabular}{|c|c|c|c|c|}
\hline Model & & $\beta$ & $t$ & $p$ \\
\hline \multirow[t]{2}{*}{ Main effects } & PHQ-9 & 0.35 & 14.6 & $<.001$ \\
\hline & Gender & -0.47 & -19.6 & $<.001$ \\
\hline Interaction & PHQ-9 $\times$ Gender & -0.09 & -3.89 & $<.001$ \\
\hline \multirow[t]{2}{*}{ Main effects } & Fantasies of sexual coercion & 0.20 & 7.04 & $<.001$ \\
\hline & Gender & -0.35 & -12.63 & $<.001$ \\
\hline Interaction & Fantasies of sexual coercion $\times$ Gender & -0.01 & -0.21 & .834 \\
\hline \multirow[t]{2}{*}{ Main effects } & Acts of sexual coercion & 0.21 & 6.67 & $<.001$ \\
\hline & Gender & -0.38 & -14.22 & $<.001$ \\
\hline Interaction & Acts of sexual coercion $\times$ Gender & 0.07 & 2.17 & .031 \\
\hline \multirow[t]{2}{*}{ Main effects } & s-IATsex & 0.74 & 28.57 & $<.001$ \\
\hline & Gender & -0.05 & -2.02 & .043 \\
\hline Interaction & s-IATsex $\times$ Gender & 0.06 & 3.0 & .006 \\
\hline \multirow[t]{2}{*}{ Main effects } & TSO-experience with a partner & 0.19 & 6.0 & $<.001$ \\
\hline & Gender & -0.41 & -16.0 & $<.001$ \\
\hline Interaction & TSO-experience with a partner $\times$ Gender & 0.13 & 4.08 & $<.001$ \\
\hline \multirow{2}{*}{ Main effects } & TSO-masturbation & 0.36 & 12.19 & $<.001$ \\
\hline & Gender & -0.32 & -12.16 & $<.001$ \\
\hline Interaction & TSO-masturbation $\times$ Gender & 0.15 & 5.37 & $<.001$ \\
\hline \multirow[t]{2}{*}{ Main effects } & Number of partners (past year) & 0.24 & 7.8 & $<.001$ \\
\hline & Gender & -0.41 & -15.84 & $<.001$ \\
\hline Interaction & Number of partners (past year) $\times$ Gender & 0.06 & 1.84 & .066 \\
\hline \multirow[t]{2}{*}{ Main effects } & Pornography consumption (time) & 0.61 & 11.36 & $<.001$ \\
\hline & Gender & -0.24 & -7.74 & $<.001$ \\
\hline Interaction & Pornography consumption (time) $\times$ Gender & 0.36 & 7.01 & $<.001$ \\
\hline
\end{tabular}

Note. PHQ-9: score of Patient Health Questionnaire-9 measuring depressive symptoms; s-IATsex: score of short Internet Addiction Test Sex measuring problematic cybersex; TSO-coitus: number of total sexual outlets experienced with a partner; TSO-masturbation: number of total sexual outlets experienced through masturbation.
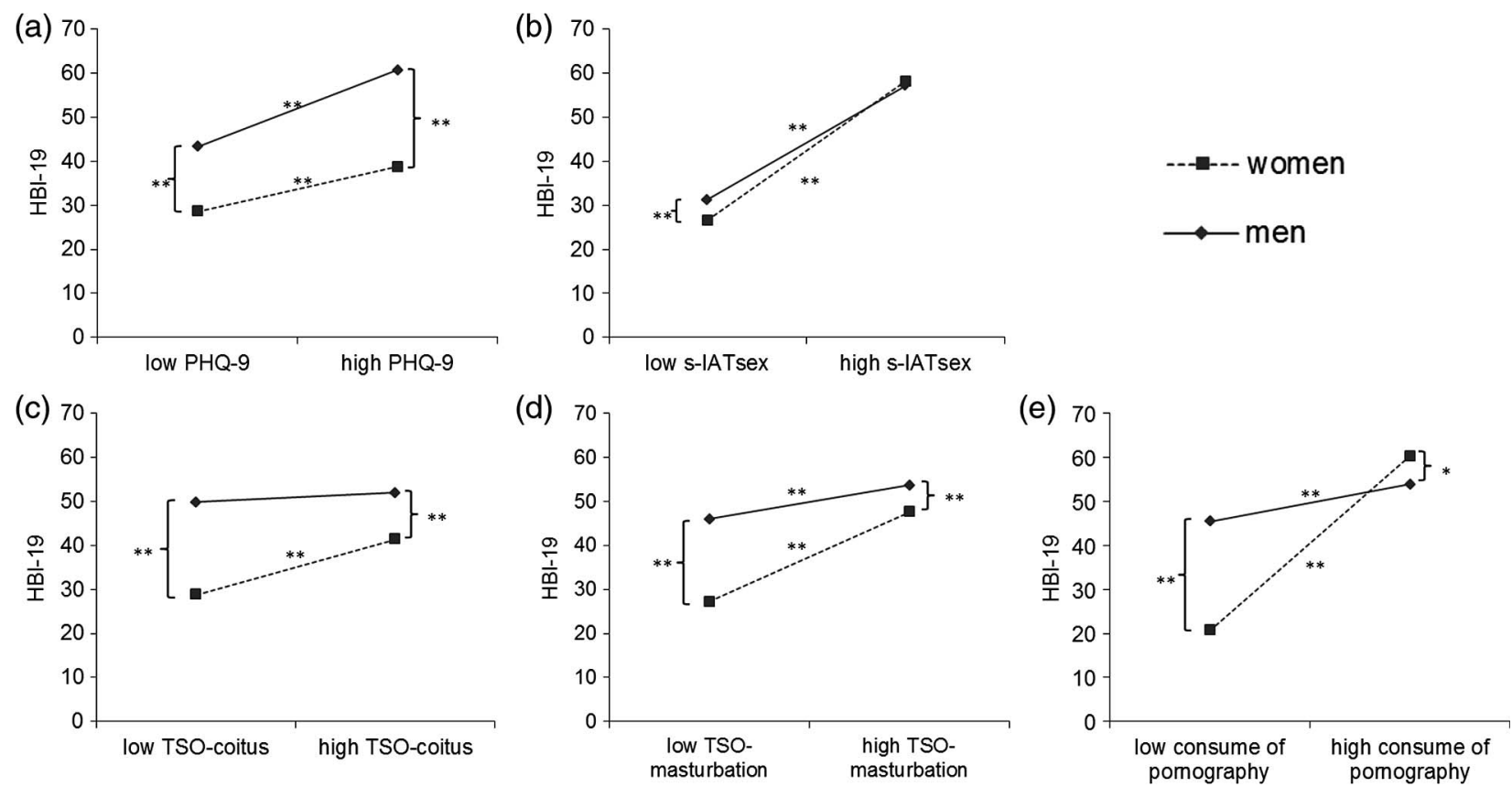

Figure 2. Simple slopes. Note. Low values for the variables are estimates for subjects with values $1 S D$ below the group's mean and high values are estimates for subjects with values $1 S D$ above the group's mean. PHQ-9: score of Patient Health Questionnaire-9 measuring depressive symptoms. s-IATsex: score of short Internet Addiction Test Sex measuring problematic cybersex. TSO-coitus: number of total sexual outlets experienced with a partner; TSO-masturbation: number of total sexual outlets experienced through masturbation. ${ }^{*} p<.05 .{ }^{* *} p<.01$ (asymptotic significances; two-tailed) 
of sexual partners in the past year, and time of pornography consumption, fantasies, and acts of sexual coercion are associated with levels of HD symptom severity. Moreover, the gender of participants had an impact on the associations of TSO and time of pornography consumption with levels of HD symptom severity. High prevalence of depression is one of society's major health problems, with suicide rates remaining high (APA, 2013). Our data revealed a significant association between symptoms of depression and HD symptoms $(r=.29)$, which leads us to suspect a bidirectional association between depression and levels of HD symptom severity. This finding is in line with a meta-analysis that suggested a moderate, positive relation $(r=.34)$ on the association of depressive and HD symptoms (Schultz, Hook, Davis, Penberthy, \& Reid, 2014). Depressive symptoms usually come along with decreased sexual interest (Bancroft et al., 2003). However, as has been shown before, in some men (Bancroft et al., 2003) and women (Opitz, Tsytsarev, \& Froh, 2009), depressive symptoms may be associated with increased interest in sexual behavior. The moderated hierarchical regression analyses in this study showed that elevated levels of depressive symptoms predicted increased levels of HD symptom severity in both genders. A possible explanation is that hypersexual behavior is used to deal with problems, stress, or unpleasant feelings (Schultz et al., 2014). Soothing dysphoric mood states or stress through sexual behavior is dysfunctional in many cases, because the relief that occurs from sexual activities is limited in time and the sexual activity per se does not solve problems (Schultz et al., 2014). In our sample, high symptoms of depression were slightly stronger associated with levels of HD symptom severity in men than in women. Perhaps, coping through sexual behavior may be somewhat elevated in men, because historically sexual behavior was more accepted in men (Fugere, Cousins, Riggs, \& Haerich, 2008).

As expected, moderated regression analyses revealed that sexual variables such as problematic cybersex, TSOmasturbation, number of sexual partners in the past year, and time of pornography consumption were significant predictors of levels of HD symptom severity in both gender. The main results regarding sexual variables are that simple slopes indicated different effects of gender on the association of TSO experienced with a partner or through masturbation as well as pornography consumption on levels of HD symptom severity. Moreover, analyses showed that men reported more sexual activity than women. If one would investigate the total population, the mean number of opposite-sex partners reported by men and women should be equal, but men frequently report more opposite-sex partners than women (Mitchell et al., 2019). If previous sexual partners were estimated rather than counted, men seem to overestimate the number of partners (Mitchell et al., 2019). Accordingly, in our sample, men report more sexual partners than women. Moderated regression analyses revealed that women with a high TSO and pornography consumption reported more levels of HD symptom severity. Possibly, women in our sample underreport their sexual partners because they fear social disapproval for transgressing gender norms (Alexander \& Fisher, 2003). Simple slopes indicated that the level of sexual activity in men was less associated with the levels of HD symptom severity compared to women. Moreover, in men, the amount of partnered sexual activity seemed to have no influence on reported levels of HD symptom severity. Acting out sexually in men may be more isolative (e.g., pornography consumption and masturbation) compared to acting out sexually in women (sexual encounters with different partners; Schultz et al., 2014). This was also present in our sample through an elevated time of pornography consumption and higher rates of TSO-masturbation in men compared to women. We argue that hypersexual behavior may result in a conflict with women's expected stereotypical behavior and hence the increased perceived distress through women's sexual behavior; while, in men, a high level of sexual activity is more accepted. That is, women with the high levels of sexual activity feel distressed because they compare their behavior with their female environment, which is characterized by higher sexual inhibition and lower sexual excitation (Janssen \& Bancroft, 2006). Higher sexual inhibition in women probably stems from a more selective sexuality in women (Sjoberg \& Cole, 2018; Trivers, 1972). On the other hand, men might even be appreciated by their peers for their hypersexual behavior, resulting in less suffering. Moreover, future studies should include measures of social norms and sexual arousal, which seems to be associated with sexual activity in addition to levels of HD symptom severity measured by questionnaires (Walton, Lykins, \& Bhullar, 2016).

Sexual coercion presents a clear threat to a person's physical and mental health, and is frequently reported by both children (Osterheider et al., 2011) and adults (Ellsberg, Jansen, Heise, Watts, \& Garcia-Moreno, 2008). This study shows that in both women and men, levels of HD symptom severity were associated with elevated rates of sexual fantasies involving coercion and a high rate of actual sexual coercion. Fantasizing about forcing someone to have sex is not uncommon, in both women and men (Joyal, Cossette, \& Lapierre, 2014). Large online samples indicate that about $11 \%$ of women and $22 \%$ of men share this fantasy (Joyal et al., 2014). We found even higher numbers of about $21 \%$ of women and about $59 \%$ of men who have reported this fantasy. Only a small proportion of sexual offenses reported to police are committed by females, but the actual amount of undetected offenses is expected to be much higher (Cortoni, Babchishin, \& Rat, 2016; Vandiver \& Kercher, 2004). These results are consistent with recent findings of increased sexual coercive behavior in a group of men diagnosed with proposed levels of HD symptom severity compared to healthy controls (Engel et al., 2019). Furthermore, hypersexuality has been found to be an empirically supported risk factor for sexual recidivism (Mann, Hanson, \& Thornton, 2010). Despite the existing studies on fantasies and acts of sexual coercion, it remains difficult to draw causal conclusions from these findings. One possible explanation may be that higher sexual desire and increased sexual coping behavior in both women and men with levels of HD symptom severity may result in a clash of sexual interest in their social environment and hence the increased rates of sexual coercive behavior. Another possible path to sexual coercive fantasies and behavior may lie in an escalating 
sexual interest, possibly induced by habitation to common sexual practices. Novelty seeking has been found to be associated with hypersexual behavior (Banca et al., 2016) and fantasies of sexual coercion may function as a new, sexually interesting stimulus in individuals with tendencies toward hypersexuality. Future experimental studies should investigate the connection of sexually deviant behavior and hypersexuality and explore treatments for individuals who are at high risk of offending.

\section{Limitations}

This study contributes to the current state of research through its large sample size and many significant results with large effect sizes. However, there are some limitations that should be considered. This study used only the HBI-19 to assess levels of HD symptom severity. A clinical interview would have been necessary to classify individuals into groups. Moreover, the level of sexual desire was not controlled for in our assessments. In this study, we limited the number of assessments used in order to take up as little of participants' time as possible because we did not compensate them for participating. Due to the self-report questionnaires used in this study, causal conclusions cannot be drawn from the data. Future studies should consider using longitudinal designs to gain insight into the etiology of hypersexual behaviors. The items used to obtain information about sexual coercion were fundamental. Future research should use assessments that ask questions more indirectly and cover cognitive distortions about rape, for example, the Bumby Rape Scale (Bumby, 1996). Finally, the sample used in this study is not representative of the general population. For example, educational levels were higher in our sample than is typical for the population. The number of levels of HD symptom severity in our sample was undoubtedly high compared with symptoms in the general population because the weblink to the study was posted among others in forums for individuals with levels of HD symptom severity. In addition, many newspapers that reported on our article used the term "sexual addiction" in their headlines, which may have resulted in a greater interest of individuals with levels of HD symptom severity in participating.

\section{CONCLUSIONS}

In summary, this is one of the first studies to investigate individual characteristics of hypersexuality in women and men. We would like to point out that hypersexual behavior is often associated with severe intra- and interpersonal difficulties that can negatively affect the well-being of both the individuals who report these symptoms and those around them. Thus, our investigation suggests that treatment of HD should also focus on comorbid disorders, especially depression, as well as potential fantasies and behaviors involving sexual coercion toward others. Furthermore, possibly resulting from moral disapproval, sexual activity seems to be a better predictor for hypersexual behavior in women than in men.
Funding sources: No financial support was received for this study.

Authors' contribution: JE, TK, CS, JK, AK, and UH contributed to concept and design. AK, MV, and JE contributed to data collection. JE and AK contributed to statistical analysis. JE, AK, MV, CS, I-AH, JK, and TK contributed to analysis and interpretation. $\mathrm{UH}$ and $\mathrm{TK}$ contributed to study supervision.

Conflict of interest: The authors declare no conflict of interest.

\section{REFERENCES}

Alexander, M. G., \& Fisher, T. D. (2003). Truth and consequences: Using the bogus pipeline to examine sex differences in selfreported sexuality sex stereotypes. Journal of Sex Research, 40(1), 27-35. doi:10.1080/00224490309552164

American Psychiatric Association [APA]. (2013). Diagnostic and statistical manual of mental disorders (5th ed.). Arlington, VA: American Psychiatric Association.

Banca, P., Morris, L. S., Mitchell, S., Harrison, N. A., Potenza, M. N., \& Voon, V. (2016). Novelty, conditioning and attentional bias to sexual rewards. Journal of Psychiatric Research, 72, 91-101. doi:10.1016/j.jpsychires.2015. 10.017

Bancroft, J., Janssen, E., Ph, D., Strong, D., Carnes, L., Vukadinovic, Z., \& Long, J. S. (2003). The relation between mood and sexuality in heterosexual men. Archives of Sexual Behavior, 32(3), 217-230. doi:10.1023/A:1023409516739

Black, M. C., Basile, K. C., Smith, S. G., Walters, M. L., Merrick, M. T., Chen, J., \& Stevens, M. R. (2011). National intimate partner and sexual violence survey 2010 summary report (pp. 1-124). Atlanta, GA: National Center for Injury Prevention and Control, Centers for Disease Control and Prevention.

Böthe, B., Bartók, R., Tóth-király, I., Reid, R. C., Griffiths, M. D., Demetrovics, Z., \& Orosz, G. (2018). Hypersexuality, gender, and sexual orientation: A large-scale psychometric survey study. Archives of Sexual Behavior, 47(8), 2265-2276. doi:10.1007/s10508-018-1201-z

Bőthe, B., Kovács, M., Tóth-király, I., Reid, R. C., Mark, D., Orosz, G., \& Demetrovics, Z. (2018). The psychometric properties of the Hypersexual Behavior Inventory using a large-scale nonclinical sample. The Journal of Sex Research, 56(2), 180-190. doi:10.1080/00224499.2018.1494262

Brand, M., Laier, C., Pawlikowski, M., Schächtle, U., Schöler, T., \& Altstötter-Gleich, C. (2011). Watching pornographic pictures on the Internet: Role of sexual arousal ratings and psychological-psychiatric symptoms for using Internet sex sites excessively. Cyberpsychology, Behavior, and Social Networking, 14(6), 371-377. doi:10.1089/cyber.2010.0222

Bumby, K. M. (1996). Assessing the cognitive distortions of child molesters and rapists: Development and validation of the MOLEST and RAPE scales. Sexual Abuse: A Journal of Research and Treatment, 8(1), 37-54. doi:10.1177/10790632 9600800105 
Cooper, A. (1998). Sexuality and the Internet: Surfing into the new millennium. CyberPsychology \& Behavior, 1(2), 187-193. doi:10.1089/cpb.1998.1.187

Cortoni, F., Babchishin, K. M., \& Rat, C. (2016). The proportion of sexual offenders who are female is higher than thought. Criminal Justice and Behavior, 44(2), 145-162. doi:10.1177/ 0093854816658923

Dickenson, J. A., Gleason, N., Coleman, E., \& Miner, M. H. (2018). Prevalence of distress associated with difficulty controlling sexual urges, feelings, and behaviors in the United States. JAMA Network Open, 1(7), e184468. doi:10.1001/ jamanetworkopen.2018.4468

Ellsberg, M., Jansen, H., Heise, L., Watts, C., \& Garcia-Moreno, C. (2008). Intimate partner violence and women's physical and mental health in the WHO multi-country study on women's health and domestic violence: An observational study. The Lancet, 371(9619), 1165-1172. doi:10.1016/S01406736(08)60522-X

Engel, J., Veit, M., Sinke, C., Heitland, I., Kneer, J., Hillemacher, T., Hartmann, U., \& Kruger, T. H. C. (2019). Same same but different: A clinical characterization of men with hypersexual disorder in the sex @ brain study. Journal of Clinical Medicine, 8(2), 157. doi:10.3390/jcm8020157

Fugere, M. A., Cousins, A. J., Riggs, M. L., \& Haerich, P. (2008). Sexual attitudes and double standards: A literature review focusing on participant gender and ethnic background. Sexuality \& Culture, 12(3), 169-182. doi:10.1007/s12119-0089029-7

Grant, J. E., Atmaca, M., Fineberg, N. A., Fontenelle, L. F., Matsunaga, H., Janardhan Reddy, Y. C., Simpson, H. B., Thomsen, P. H., van den Heuvel, O. A., Veale, D., Woods, D. W., \& Stein, D. J. (2014). Impulse control disorders and behavioural addictions in the ICD-11. World Psychiatry, 13(2), 125-127. doi:10.1002/wps.20115

Grubbs, J. B., Kraus, S. W., \& Perry, S. L. (2018). Self-reported addiction to pornography in a nationally representative sample: The roles of use habits, religiousness, and moral incongruence. Journal of Behavioral Addictions, 8(1), 88-93. doi:10.1556/ 2006.7.2018.134

Hald, G. M., Malamuth, N. M., \& Yuen, C. (2010). Pornography and attitudes supporting violence against women: Revisiting the relationship in nonexperimental studies. Aggressive Behavior, 36(1), 14-20. doi:10.1002/ab.20328

Janghorbani, M., \& Lam, T. H. (2003). Sexual media use by young adults in Hong Kong: Prevalence and associated factors. Archives of Sexual Behavior, 32(6), 545-553. doi:10.1023/ A:1026089511526

Janssen, E., \& Bancroft, J. (2006). The dual control model: The role of sexual inhibition \& excitation in sexual arousal and behavior. In E. Janssen (Ed.), The psychophysiology of sex (pp. 1-11). Bloomington, IN: Indiana University Press.

Joyal, C. C., Cossette, A., \& Lapierre, V. (2014). What exactly is an unusual sexual fantasy? The Journal of Sexual Medicine, 12(2), 328-340. doi:10.1111/jsm.12734

Kafka, M. P. (2010). Hypersexual disorder: A proposed diagnosis for DSM-V. Archives of Sexual Behavior, 39(2), 377-400. doi:10.1007/s10508-009-9574-7

Kafka, M. P., \& Hennen, J. (2002). A DSM-IV Axis I comorbidity study of males $(n=120)$ with paraphilias and paraphilia-related disorders. Sexual Abuse: A Journal of Research and Treatment, 14(4), 349-366. doi:10.1177/107906320201400405
Kraus, S. W., Krueger, R. B., Briken, P., First, M. B., Stein, D. J., Kaplan, M. S., \& Reed, G. M. (2018). Compulsive sexual behaviour disorder in the ICD-11. World Psychiatry, 17(1), 109-109. doi:10.1002/wps.20499

Kroenke, K., \& Spitzer, R. L. (2002). The PHQ-9: A new depression diagnostic and severity measure. Psychiatric Annals, 32(9), 509-515. doi:10.3928/0048-5713-20020901-06

Löwe, B., Kroenke, K., Herzog, W., \& Gräfe, K. (2004). Measuring depression outcome with a brief self-report instrument: Sensitivity to change of the Patient Health Questionnaire (PHQ-9). Journal of Affective Disorders, 81(1), 61-66. doi:10.1016/S0165-0327(03)00198-8

Mann, R. E., Hanson, R. K., \& Thornton, D. (2010). Assessing risk for sexual recidivism: Some proposals on the nature of psychologically meaningful risk factors. Sexual Abuse: A Journal of Research and Treatment, 22(2), 191-191. doi:10.1177/ 1079063210366039

Mitchell, K. R., Mercer, C. H., Prah, P., Clifton, S., Tanton, C., Wellings, K., \& Copas, A. (2019). Why do men report more opposite-sex sexual partners than women? Analysis of the gender discrepancy in a British national probability survey. The Journal of Sex Research, 56(1), 1-8. doi:10.1080/ 00224499.2018 .1481193

Montgomery-Graham, S. (2017). Conceptualization and assessment of hypersexual disorder: A systematic review of the literature. Sexual Medicine Reviews, 5(2), 146-162. doi:10.1016/ j.sxmr.2016.11.001

Opitz, D. M., Tsytsarev, S. V., \& Froh, J. (2009). Women's sexual addiction and family dynamics, depression and substance abuse. Sexual Addiction \& Compulsivity: The Journal of Treatment \& Prevention, 16(4), 37-41. doi:10.1080/10720160903375749

Osterheider, M., Banse, R., Briken, P., Goldbeck, L., Hoyer, J., Santtila, P., Turner, D., \& Eisenbarth, H. (2011). Frequency, etiological models and consequences of child and adolescent sexual abuse: Aims and goals of the German multi-site MiKADO project. Sexual Offender Treatment, 6(2), 1-7. Retrieved from http://www.sexual-offender-treatment. org/105.html

Raymond, N. C., Coleman, E., \& Miner, M. H. (2003). Psychiatric comorbidity and compulsive/impulsive traits in compulsive sexual behavior. Comprehensive Psychiatry, 44(5), 370-380. doi:10.1016/S0010-440X(03)00110-X

Reid, R. C., Carpenter, B. N., Spackman, M., \& Willes, D. L. (2008). Alexithymia, emotional instability, and vulnerability to stress proneness in patients seeking help for hypersexual behavior. Journal of Sex and Marital Therapy, 34(2), 133-149. doi:10.1080/00926230701636197

Reid, R. C., Garos, S., Carpenter, B. N., \& Coleman, E. (2011). A surprising finding related to executive control in a patient sample of hypersexual men. The Journal of Sexual Medicine, 8(8), 2227-2236. doi:10.1111/j.1743-6109.2011.02314.x

Rissel, C., Richters, J., De Visser, R. O., Mckee, A., Yeung, A., Rissel, C., \& Caruana, T. (2016). A profile of pornography users in Australia: Findings from the second Australian study of health and relationships. The Journal of Sex Research, 54(2), 227-240. doi:10.1080/00224499.2016.1191597

Schultz, K., Hook, J. N., Davis, D. E., Penberthy, J. K., \& Reid, R. C. (2014). Nonparaphilic hypersexual behavior and depressive symptoms: A meta-analytic review of the literature. Journal of Sex \& Marital Therapy, 40(6), 477-487. doi:10.1080/0092623X.2013.772551 
Sjoberg, E. A., \& Cole, G. G. (2018). Sex differences on the Go/ No-Go test of inhibition. Archives of Sexual Behavior, 47(2), 537-542. doi:10.1007/s10508-017-1010-9

Skegg, K., Nada-Raja, S., Dickson, N., \& Paul, C. (2010). "Perceived out of control" sexual behavior in a cohort of young adults from the Dunedin Multidisciplinary Health and Development study. Archives of Sexual Behavior, 39(4), 968-978. doi:10.1007/s10508-009-9504-8

Træen, B., Nilsen, T. S., \& Stigum, H. (2006). Use of pornography in traditional media and on the Internet in Norway. Journal of Sex Research, 43(3), 245-254. doi:10.1080/0022449060 9552323

Trivers, R. L. (1972). Parental investment and sexual selection. In B. Campbell (Ed.), Sexual selection and the descent of man: 1871-1971 (pp. 136-179). Chicago, IL: Aldine.

Vandiver, D. M., \& Kercher, G. (2004). Offender and victim characteristics of registered female sexual offenders in Texas: A proposed typology of female sexual offenders. Sexual
Abuse: A Journal of Research and Treatment, 16(2), 121-137. doi:10.1177/107906320401600203

Walton, M., Cantor, J., Bhullar, N., \& Lykins, A. (2017). Hypersexuality: A critical review and introduction to the "sexhavior cycle." Archives of Sexual Behavior, 46(8), 2231-2251. doi:10.1007/s10508-017-0991-8

Walton, M. T., Lykins, A. D., \& Bhullar, N. (2016). Sexual arousal and sexual activity frequency: Implications for understanding hypersexuality. Archives of Sexual Behavior, 45(4), 777-782. doi:10.1007/s10508-016-0727-1

Weiss, D. (2004). The prevalence of depression in male sex addicts residing in the United States. Sexual Addiction \& Compulsivity, 11(1-2), 57-69. doi:10.1080/10720160490 458247

Wéry, A., \& Billieux, J. (2017). Addictive behaviors problematic cybersex: Conceptualization, assessment, and treatment. Addictive Behaviors, 64, 238-246. doi:10.1016/j.addbeh.2015. 11.007 